\title{
Supplies and Non-Drug Investigational Product Import Document
}

National Cancer Institute

\section{Source}

National Cancer Institute. Supplies and Non-Drug Investigational Product Import

Document. NCI Thesaurus. Code C115738.

Records of the import of laboratory supplies, or a non-drug investigational product (IP). 